\title{
Commentary: Keep it short and keep it cold-ish
}

\author{
John Bozinovski, MD, MSc
}

\author{
From the Division of Cardiac Surgery, University of British Columbia and the Royal Jubilee Hospital, Victoria, \\ British Columbia, Canada. \\ Disclosures: Author has nothing to disclose with regard to commercial support. \\ Received for publication Feb 16, 2019; accepted for publication Feb 18, 2019; available ahead of print April 5, \\ 2019. \\ Address for reprints: John Bozinovski, MD, MSc, 106-2020 Richmond Rd, Victoria, British Columbia V8R-6R5, \\ Canada (E-mail: john.bozinovski@ubc.ca). \\ J Thorac Cardiovasc Surg 2020;159:388-9 \\ $0022-5223 / \$ 36.00$ \\ Copyright $\Subset 2019$ by The American Association for Thoracic Surgery \\ https://doi.org/10.1016/j.jtcvs.2019.02.071
}

The report in this issue of the Journal from Wang and colleagues ${ }^{1}$ retrospectively analyzing perioperative outcomes in more than 1700 patients undergoing aortic arch surgery with unilateral antegrade cerebral perfusion is notable for many things, such as the volume of procedures performed, the characteristics of the patients operated on, and the reported outcomes. On average, this single center performed more than 5 total arch operations per week during the 7 years of the study. The overwhelming majority of the operations were performed to treat aortic dissections (91\%), with only $8 \%$ of patients having aneurysm as the indication. This differs from the cohort in most aortic surgeons' practices. Further, one-quarter of the type A dissections were chronic, and more than $40 \%$ were chronic or subacute. Again, this is not common in most practices. The patients were very young, averaging 47 years of age, and predominately male. For various reasons, and not always obvious ones, younger ${ }^{2}$ and male ${ }^{3}$ patients have better outcomes when undergoing aortic arch surgery under hypothermic circulatory arrest. This fact is likely to have contributed, in part, to the exceptional outcomes observed.

The study of Wang and colleagues ${ }^{1}$ confirmed intuitively obvious risk factors for 30-day mortality, such as preoperative coma and type I aortic dissection, and less obvious ones, such as need for coronary bypass grafting and extraanatomic bypass. Whether it is the underlying disease necessitating these procedures or something associated with the performance of these procedures that confers that risk is to be determined.

Although a low stroke rate $(2.8 \%)$ was reported, it should be viewed with limited confidence, because the incidence will vary depending on whether stroke is routinely and consistently assessed, when it is assessed, by whom it is assessed, and how that assessment is made. Unless a vigorous and dedicated protocol to assess stroke is included in a study, it is difficult to assign confidence to rates of stroke.

Generally speaking, the advent of cerebral perfusion strategies has resulted in arch surgery being performed at warmer temperatures. ${ }^{4}$ The assumption is that if the end

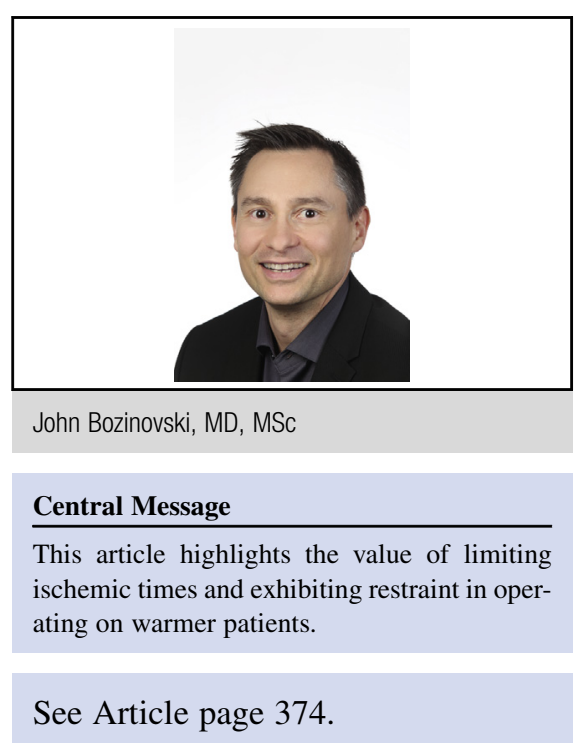

organs are not ischemic for prolonged periods, colder temperatures are not necessary and, in fact, could be harmful. Although the population in this particular study is atypical of most practices, the findings still apply to aortic surgery in general, and we can be fairly confident in extrapolating their results to our own practices. This study may have placed a cautionary cairn by finding that mortality and permanent neurologic dysfunction increased with temperatures greater than $25^{\circ} \mathrm{C}$ and $24^{\circ} \mathrm{C}$, respectively. Although we tend to focus our attention on attenuating stroke during arch surgery, organs other than the brain, such as the spine and kidneys, are also in jeopardy. Again, this study suggests that temperatures greater than $24^{\circ} \mathrm{C}$ result in an increased probability of renal injury and a more profoundly increased probability of paraplegia. Further, limiting lower body hypothermic arrest time was protective of survival and renal function and against paraplegia, with time beyond $40 \mathrm{mi}-$ nutes marking a progressively worsening outcome to paraplegia. Whether one uses an arch first technique or the strategy described in the article of Wang and colleagues, the principle of limiting unilateral cerebral ischemia and lower body ischemia to the best of our ability is to be maintained.

\section{References}

1. Wang X, Yang F, Zhu J, Liu Y, Sun L, Hou X. Aortic arch surgery with hypothermic circulatory arrest and unilateral antegrade cerebral perfusion: perioperative outcomes. J Thorac Cardiovasc Surg. 2020;159:374-87.e4.

2. Williams JB, Peterson ED, Zhao Y, O'Brien SM, Andersen ND, Miller DC, et al. Contemporary results for proximal aortic replacement in North America. J Am Coll Cardiol. 2012;60:1156-62. 
3. Chung J, Stevens LM, Ouzounian M, El-Hamamsy I, Bouhout I, Dagenais F, et al; Canadian Thoracic Aortic Collaborative. Sex-related differences in patients undergoing thoracic aortic surgery: evidence from the Canadian thoracic aortic collaborative. Circulation. 2019;139:1177-84.

4. Urbanski P, Lenos A, Bougioukakis P, Neophytou I, Zacher M, Diegeler A. Mild-to-moderate hypothermia in aortic arch surgery using circulatory arrest: a change of paradigm? Eur J Cardiothorac Surg. 2012;41:185-91.

5. Kamiya H, Hagl C, Kropivnitskaya I, Bothig D, Kallenbach K, Khaladj N, et al The safety of moderate hypothermic lower body circulatory arrest with selective cerebral perfusion: a propensity score analysis. J Thorac Cardiovasc Surg. 2012;133:501-9. 